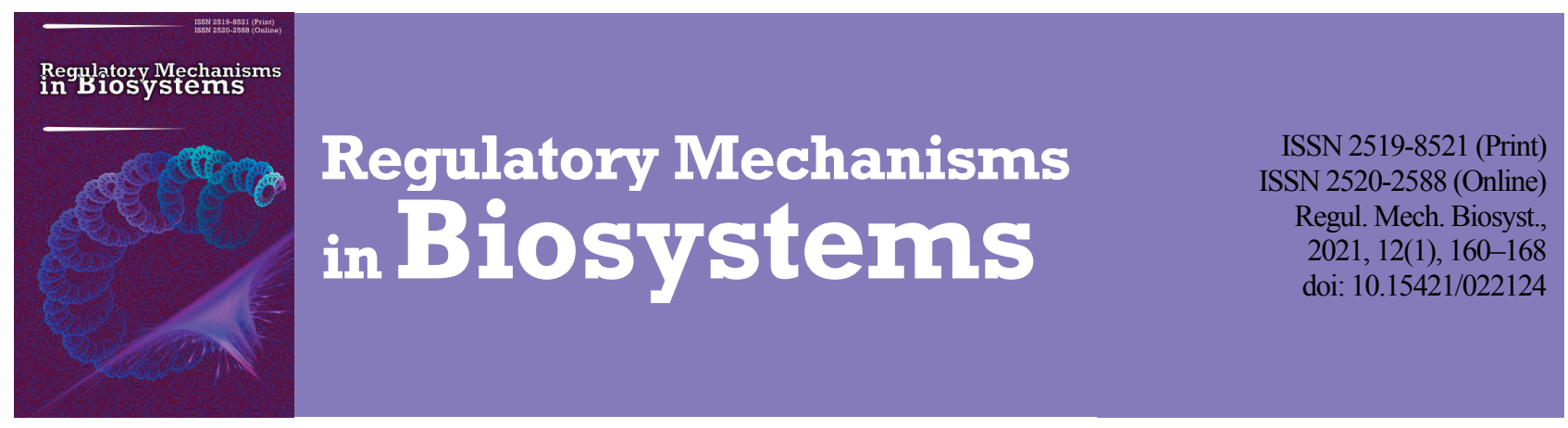

\title{
Staphylococcus aureus and $S$. epidermidis in biological systems of hospital environment: Antibiotic resistance patterns in regions of Ukraine
}

\author{
A. V. Berezhna*, V. O. Tertyshnyi**, V. I. Makarova*, T. O. Chumachenko* \\ *Kharkiv National Medical University, Kharkiv, Ukraine \\ **SI Poltava Oblast Laboratory Center of the MoH of Ukraine, Poltava, Ukraine
}

Article info

Received 19.02.2021

Received in revised form 10.03.2021

Accepted 11.03.2021

Kharkiv National

Medical University

Nauky av., 4,

Kharkiv, 61022, Ukraine

$\mathrm{Tel} \cdot+38-067-358-12-08$

E-mail:

a.v.berezhna@gmail.com

SI Poltava Oblast Laborato ry Center of the $\mathrm{MoH}$ of Ukraine, Vatutina st.

35-a, Poltava,

36039, Ukraine.

Tel.: +38-066-882-31-79

E-mail:

vladissimo11@gmail.com

Berezhna, A. V., Tertyshnyi, V. O., Makarova, V. I., \& Chumachenko, T. O. (2021). Staphylococcus aureus and S. epidermidis in biological systems of hospital environment: Antibiotic resistance patterns in regions of Ukraine. Regulatory Mechanisms in Biosystems, 12(1), 160-168. doi:10.15421/022124

Staphylococcus bacteria are ubiquitous and often circulate in the biological systems of the hospital environment. Staphylococci have developed antibiotic resistance mechanisms resulting in a significant medical and economic burden to the healthcare system. The goal of our research was to conduct a comparative analysis of resistance to antibiotics in $S$. aureus and $S$. epidermidis isolates found in surgical hospitals in Kharkiv and Poltava regions. In 2013 through 2019, 151,015 and 98,754 tests were made by discdiffusion method to identify the sensitivity in the S. aureus strains to antibiotics in Kharkiv and Poltava regions respectively. In 20132015, 15,589 tests were made in Kharkiv region to identify antibiotics sensitivity in S. epidermidis strains. Comparison of antibiotic resistance of the $S$. aureus strains in Kharkiv and Poltava regions was performed using the Pearson Chi-square test $\left(\chi^{2}\right)$ and Fisher's exact test. The proportion of S. aureus strains resistant to penicillins, cephalosporins, carbapenems, aminoglycosides, and macrolides was higher in Kharkiv region in terms of statistical validity than in Poltava region. Overall, the proportion of S. aureus strains resistant to lincozamids, tetracycline antibiotics, and fluoroquinolones in Poltava region was higher in terms of statistical validity than in Kharkiv region. An analysis of resistance of $S$. aureus strains to linezolid demonstrated that in Poltava region the proportion of resistant microorganisms was higher in terms of statistical validity in 2013-2014 and in 2016-2018. In Kharkiv region, in 2013 and in 2014, $96.3 \%$ and $89.1 \%$ of isolated strains of $S$. aureus respectively, were resistant to vancomycin. In 2019 , more than a quarter of the located isolates (26.6\%) in Poltava region were resistant to this antibiotic. The analysis of the dynamic of resistance in S. epidermidis isolates demonstrated that in 2015 nearly half of the isolates located in Kharkiv region were insensitive to penicillin antibiotics. Between 2013 and 2015, the spread of resistance to cephalosporins, aminoglycosides, macrolides, and fluoroquinolones among the S. epidermidis isolates noticeably increased. When S. epidermidis resistance to vancomycin was analyzed, a decrease in the proportion of resistant strains from $88.0 \%$ in 2013 to $8.7 \%$ in 2015 was noted. A promising direction for further research is the creation of passports of microorganism resistance in the regions and various health-care settings, as well as the creation of a unified national database network on microorganism resistance using modern methodologies for determining the phenotypes and genotypes of microorganisms.

Keywords: healthcare-associated infections; catheter-related bloodstream infections; biofilms; infection control; bacteremia; genomic variability.

\section{Introduction}

Bacteria of the Staphylococcus genus, especially S. aureus are among most frequently encountered infectious agents associated with rendering medical aid (Canadian Nosocomial Infection Surveillance Program, 2020; Voidazan et al., 2020). This is partially due to the fact that staphylococci colonize the mucous membranes and skin of humans. The nose is considered the most frequent localization of $S$. aureus (Wertheim et al., 2005; Brown et al., 2014). Extranasal localizations of S. aureus include the skin, crotch area, armpits, and the gastrointestinal tract. It should be noted that a nasal $S$. aureus carrier is prone to be a source of extranasal transmission. For instance, $90 \%$ of $S$. aureus nasal carriers usually have the skin on their hands contaminated as well (Wertheim et al., 2005). Another potentially dangerous hospital infection pathogen is $S$. epidermidis. Microorganisms of this genus are referred to resident microflora of the human external surface and are usually normal representatives of the microbiocenosis of every healthy person's skin, which is also a significant link in the pathogenesis of infections associated with rendering of medical aid (Hellmark et al., 2013). Previously published researches point to the existing problem of incidence of methicillin-resistant genotypes of S. aureus and S. epidermidis in healthcare workers at hospitals (Du et al., 2013; Widerström et al., 2016; Sharma et al., 2019). In cases of violation of aseptic and antiseptic rules and improper observance of hand hygiene, microorganisms that are on medical personnel's skin are transmitted to patients, medical devices, equipment, and other objects of the medical environment. When invasive manipulations like catheterization of vessels are conducted, microorganisms may pass from medical personnel's hands to the surface of a vessel catheter and be the cause of development of catheter-related bloodstream infections (Cherifi et al., 2014)

It is general knowledge that patients in hospitals have at least one peripheral intravenous catheter installed in $30 \%$ to $80 \%$ of cases (Zhang et al., 2016; Aghdassi et al., 2019). The patients, who need a transfusion of massive amounts of liquid, total parenteral feeding, hemodialysis, or for other reasons, have central venous catheters installed (Smith \& Nolan, 2013). Considering the broad application of vessel appliances (including peripheral intravenous catheters) in medical practice, infectious complications associated with vessels' catheterization account for a large share of infections associated with health care provision. The incidence of blood- 
stream infections connected with application of peripheral intravenous catheters varies from $0.0 \%$ to $2.2 \%$, amounting on average to $0.18 \%$, with the incidence of nosocomial catheter-related bloodstream infections due to peripheral venous catheters reaching $6.2 \%$ to $60.0 \%$ (Mermel, 2017). In the etiological structure of infection complications associated with peripheral and central veins catheterization, the $S$. aureus strains and coagulazonegative staphylococci, including S. epidermidis, prevail (Zhang et al., 2016; Guembe et al., 2017; Nguyen et al., 2017; Mandolfo et al., 2019; Tatsuno et al., 2019).

Due to the ability of staphylococci to produce biofilms, the infections caused by them are more difficult to treat and may develop into chronic forms. The biofilm forms of bacteria possess a considerably higher resistance to antibiotics than the plankton forms (Wu et al., 2003; Costerton et al., 2005; Kaplan, 2011). S. aureus strains producing biofilms possess a higher resistance level to most medications, which is prognostically an unfavourable factor in such patients' treatment (Manandhar et al., 2018).

Under conditions of growth in microorganism resistance to medications, of grave concern are bacteremia cases caused by antibiotic-resistant strains of $S$. aureus and S. epidermidis. It is established that bacteremia caused by methicillin-resistant strains of $S$. aureus is more often associated with health care provision, in particular with application of central venous catheters. In such cases, apart from considerable economic losses, the life prognosis for patients is unfavourable. The mortality in a 28-day-period from methicillin-resistant $S$. aureus bacteria is 1.6 times higher than from bacteremia caused by $S$. aureus strains producing penicillinase (Jokinen et al., 2017).

Identifying microorganism resistance and determining the mechanisms influencing their resistance to antibiotics and their ability to produce biofilm forms, as well as an increase in their virulence and pathogenicity should be one of priority directions in the healthcare system of any state. Due to staphylococci's (especially $S$. aureus) possessing a high degree of adaptability and genomic variability (Deurenberg et al., 2007; Deurenberg \& Stobberingh, 2008; Lindsay, 2010; Conlan et al., 2012), it is necessary to maintain a permanent monitoring of their resistance.

In 2018, the results of a wide-scale multicentered epidemiology research project on determining antibiotic-resistance (Survey of Antibiotic Resistance, SOAR) concerning Ukraine and Slovakia were published. On the example of non-hospital respiratory infections agents Streptococcus pneumoniae and Haemophilus influenzae, territorial differences in the resistance level of the located isolates in the two neighbouring countries were found (Torumkuney et al., 2018). Overall, other studies on microorganism resistance to antibiotics, currently conducted in Ukraine, are narrowly specialized and do not encompass the problem in general.

It should be noted that there are differences in antibacterial resistance in organisms circulating in different departments of the same healthcare setting. For instance, the strains found in intensive care patients are often more resistant and may possess multiple resistance to antibiotics (Kollef \& Fraser, 2001; Brusselaers et al., 2011). It was also noted that in the countries with lower income levels, the burden of antibiotic resistance in intensive care units is much heavier than in the countries with high incomes (Saharman et al., 2021). Everything mentioned above points to the expediency of estimating territorial differences in staphylococci antibacterial resistance in the regions of Ukraine. Therefore, the goal of this study is to perform a comparative analysis of antibiotic resistance in $S$. aureus and S. epidermidis isolates identified in surgical hospitals of two neighbouring areas: the Kharkiv and the Poltava regions.

\section{Materials and methods}

The study included clinical specimens collected from surgical patients by bacteriological laboratories in health-care settings of Kharkiv and Poltava regions in 2013-2019. S. aureus and S. epidermidis strains were isolated and identified according to standard methods. Antibacterial resistance in staphylococci was determined using the disc-diffusion method on Mueller-Hinton agar according to Clinical and Laboratory Standards Institute Guidelines (Bauer et al., 1966; Clinical Laboratory Standards Institute, 2014). In total, 151,015 and 98,754 tests to determine antibacterial resistance of $S$. aureus in Kharkiv and Poltava regions respectively were carried out in 2013-2019 and 15,589 tests to determine antibiotic resis- tance in S. epidermidis strains in Kharkiv region were carried out in 20132015 (Table 1).

\section{Table 1}

Number of tests carried out for detecting resistance to various antibiotics in staphylococci isolates in health-care settings at bacteriological laboratories in Kharkiv and Poltava regions in 2013-2019

\begin{tabular}{|c|c|c|c|}
\hline \multirow{2}{*}{$\begin{array}{l}\text { Antibiotics group } \\
\text { or antibiotic }\end{array}$} & \multicolumn{2}{|c|}{$\begin{array}{c}\text { S. aureus } \\
(2013-2019)\end{array}$} & \multirow{2}{*}{$\begin{array}{c}\begin{array}{c}\text { S. epidermidis } \\
(2013-2015)\end{array} \\
\begin{array}{c}\text { Kharkiv } \\
\text { region }\end{array}\end{array}$} \\
\hline & $\begin{array}{c}\text { Kharkiv } \\
\text { region }\end{array}$ & $\begin{array}{c}\text { Poltava } \\
\text { region }\end{array}$ & \\
\hline Penicilins & 28,904 & 15,676 & 3,579 \\
\hline Cephalosporins & 17,359 & 5,340 & 2,818 \\
\hline Carbapenems & 3,202 & 3,038 & 396 \\
\hline Aztreonam & 0 & 0 & 11 \\
\hline Aminoglycosides & 21,144 & 10,762 & 1,782 \\
\hline Macrolides & 7,642 & 10,092 & 590 \\
\hline Lincozamides & 10,156 & 8,792 & 772 \\
\hline Tetracyclines & 3,534 & 9,934 & 596 \\
\hline Vancomycin & 7,870 & 7,120 & 939 \\
\hline Rifampicin & 5,606 & 908 & 237 \\
\hline Fluoroquinolones & 33,619 & 15,771 & 3,297 \\
\hline Linezolid & 11,210 & 8,097 & 544 \\
\hline Co-trimaxazol & 14 & 1,025 & 0 \\
\hline Chloramphenicol & 755 & 1,355 & 28 \\
\hline Phosphomicin & 0 & 293 & 0 \\
\hline Fusidic acid & 0 & 220 & 0 \\
\hline Nitrofuran derivatives & 0 & 331 & 0 \\
\hline Total & 151,015 & 98,754 & 15,589 \\
\hline
\end{tabular}

For assessment of the resistance of $S$. aureus strains, the tested antibiotics included penicillins (penicillin, benzylpenicillin, ampicillin, amoxicillin, oxacillin, carbenicillin, ampicillin/sulbactam, amoxicillin/clavulanat), cephalosporins (cefazolin, cefalotin, cephalexin, cefuroxime, cefoperazon, cefotaxime, ceftriaxone, ceftazidime, cefixime, cefepim, cefpirom, cefoperazon/sulbactam), carbapenems (imipenem, meropenem, imipenem/cilastatin), aminoglycosides (kanamycin, gentamycin, tobramycin, netilmycin, amikacin), macrolides (erythromycin, clarithromycin, azithromycin, spiramycin), lincozamides (clindamycin, lincomycin), tetracyclines (tetracycline, doxycycline, tigecycline), glycopeptides (vancomycin), an antituberculosis medicine rifampicin, fluoroquinolones (ciprofloxacin, ofloxacin, cefloxacin, norfloxacin, lomefloxacin, levofloxacin, moxifloxacin, gatifloxacin), oxazolidions (linezolid), sulphanilamides (co-trimoxazol), amphenicols (chloramphenicol) and others (phosphosycin, fusidic acid, nitrofuran derivatives).

Depending on the year and the region, the study to estimate resistance in the S. aureus strains had its peculiarities. In particular, in 2013, 2014 , 2018, 2019, no tests were made in Poltava region to estimate resistance to cephalosporin group antibiotics and carbapenems in $S$. aureus isolates. In 2013, 2014, 2018, 2019, resistance in S. aureus isolates was studied in relation to only one antibiotic of the aminoglycoside group, gentamicin, and to only one antibiotic of the macrolide group, erythromycin in Poltava region. In 2013 and 2014, the resistance in S. aureus isolates was studied in relation to only one antibiotic of the tetracycline group, tetracycline in Kharkiv region. Resistance in $S$. aureus isolates to co-trimoxazol in Kharkiv region was assessed only in 2015 and 2018. Resistance of S. aureus isolates to chloramphenicol in Kharkiv region was not assessed in 2013 and 2014. Resistance of $S$. aureus isolates to phosphomycin, fusidic acid, and nitrofuran derivatives was estimated only in Poltava region (in 2014, 2015, and 2017 - to phosphomycin; in 2016-2018 - to fusidic acid; in 2015, 2016, and 2018 - to nitrofuran derivatives).

To increase data validity, we calculated the average proportion of S. aureus isolates resistant to antibiotics groups (penicillins, cephalosporins, etc.) rather than to individual medications (with the exception of vancomycin, rifampicin, co-trimoxazol, chloramphenicol, phosphomycin, fusidic acid as the sole representatives of their antibiotic groups).

For estimation of resistance of $S$. epidermidis strains, the tested antibiotics included penicillins (penicillin, ampicillin, amoxicillin, oxacillin, carbenicillin, ampicillin/sulbactam, amoxicillin/clavulanat), cephalosporins (cefazolin, cefalotin, cephalexin, cephaklor, cefuroxime, cefoperazon, cefotaxime, ceftriaxone, ceftazidime, cefixime, ceftibuten, cefepim), carbapenems (imipenem, meropenem), monobacts (aztreonam), aminogly- 
cosides (gentamycin, tobramycin, amikacin), macrolides (erythromycin, clarithromycin, azithromycin), lincozamides (clindamycin, lincomycin), tetracyclines (tetracycline, doxycycline), glycopeptides (vancomycin), an antituberculosis medicine rifampicin, fluoroquinolones (ciprofloxacin, ofloxacin, pefloxacin, norfloxacin, lomefloxacin, levofloxacin), oxazolidions (linezolid), sulphanilamides (co-trimoxazol), amphenicols (chloramphenicol). In some years, the resistance of $S$. epidermidis isolates was tested only for one antibiotic within a certain class: in 2013 - for imipenem, aztreonam, tetracycline; in 2014 - for erythromycin, tetracycline; in 2015 - for amikacin, clindamycin and doxycycline.

By analogy with $S$. aureus, to increase data validity, we calculated the mean proportion of $S$. epidermidis isolates resistant to antibiotics of the following groups: penicillins, cephalosporins, carbapenems, aminoglycosides, macrolides, lyncozamides, and fluoroquinolones.

We performed statistical analysis using the Epi Info ${ }^{\mathrm{TM}}$ for Windows (Version 7.2). For estimation of the standard deviation of proportions we calculated the standard error (SE). Comparison of S. aureus strains' antibiotic resistance in Kharkiv and Poltava regions was performed using the Pearson Chi-square test $\left(\chi^{2}\right)$ and Fisher's exact test. The level of significance was set at $5 \%(\mathrm{P}<0.05)$.

\section{Results}

In Kharkiv region, the largest proportion of $S$. aureus strains resistant to the penicillin group drugs was identified in 2013 (62.7\%), and the smallest proportion - in 2016 (10.4\%). In Poltava region, as well as in Kharkiv region, the largest proportion of $S$. aureus isolates resistant to penicillin antibiotics was identified in 2013 (30.1\%). The smallest proportion of S. aureus strains resistant to the penicillin group drugs in Poltava region was identified in $2015(16.7 \%)$. During the whole period of the study (except 2016), the proportion of $S$. aureus strains resistant to penicillins was statistically significantly higher in Kharkiv region than in Poltava region (Fig. 1a). On the whole, in 2013-2019 the proportion of S. aureus strains resistant to the penicillin drugs group in Kharkiv region was 2.3 times statistically significantly higher than in Poltava region $(50.8 \%$ / $\mathrm{n}=14,687$ of 28,904 versus $21.8 \% / \mathrm{n}=3,412$ of 15,$676 ; \chi^{2}=3,555.9$; $\mathrm{P}<0.001)$.

The comparative analysis of $S$. aureus resistance to medications of the cephalosporin group has demonstrated in dynamics that the largest proportion of resistant S. aureus strains in both regions was identified in 2015 (39.9\% in Kharkiv region; 9.5\% in Poltava region), while the smallest proportion was identified in 2016 (4.0\% in Kharkiv region; 6.4\% in Poltava region). It should be noted that in 2015 and in 2017 the proportion of S. aureus strains resistant to cephalosporins was statistically significantly higher in Kharkiv region than in Poltava region. Nevertheless, in 2016 the proportion of $S$. aureus isolates resistant to cephalosporin antibiotics was statistically significantly higher in Poltava region (Fig. 1b). On the whole, in 2015-2017, the proportion of S. aureus strains resistant to the cephalosporin medication group was 1.7 times statistically significantly higher in Kharkiv region compared with Poltava region $(14.7 \% / \mathrm{n}=1,590$ of 10,815 versus $8.9 \% / \mathrm{n}=473$ of 5,$\left.340 ; \chi^{2}=109.6 ; \mathrm{P}<0.001\right)$.

The analysis of resistance in $S$. aureus isolates to carbapenems demonstrates that the largest proportion of resistant strains in Kharkiv region was identified in 2017 (42.0\%), while in Poltava region - in 2015 $(10.0 \%)$. The smallest proportion of S. aureus strains resistant to carbapenems was identified in Kharkiv region in $2013(9.0 \%)$, and in Poltava region - in $2016(1.7 \%)$. Statistically significant differences between the proportion of $S$. aureus strains resistant to carbapenems in Kharkiv and Poltava regions were not found in 2015 (Fig. 1c). Nevertheless, during the period from 2015 to 2017 in general, the proportion of S. aureus strains resistant to carbapenem drugs was statistically significantly higher by 3.7 times in Kharkiv region $(26.6 \% / \mathrm{n}=337$ of 1,268 versus $7.1 \% / \mathrm{n}=$ 215 of 3,$\left.038 ; \chi^{2}=304.4 ; \mathrm{P}<0.001\right)$.

When identifying the resistance in $S$. aureus isolates to aminoglycosides, the largest proportion of resistant strains in both regions was identified in 2013 (32.9\% in Kharkiv region; 22.3\% in Poltava region) The smallest proportion of resistant isolates in Kharkiv area was identified in 2016 (2.6\%), while in Poltava region - in 2014 (6.4\%). During the whole period of study (except 2016), the proportion of $S$. aureus isolates resistant to aminoglycosides was statistically significantly higher in Kharkiv region (Fig. 1d). Overall, in 2013-2019, the proportion of S. aureus strains resistant to medications of the aminoglycoside group was 1.2 times statistically significantly higher in Kharkiv region compared with Poltava region $(16.0 \% / \mathrm{n}=3,377$ of 21,144 versus $13.2 \% / \mathrm{n}=1,424$ of 10,762 ; $\left.\chi^{2}=41.9 ; \mathrm{P}<0.001\right)$.

The largest proportion of $S$. aureus isolates resistant to macrolides in Kharkiv region was identified in 2017 (55.4\%), and in Poltava region - in 2019 (42.0\%). The smallest proportion of $S$. aureus isolates resistant to macrolides in Kharkiv region was identified in 2013 (6.5\%), and in Poltava region - in $2015(12.5 \%)$. It was found that the proportion of S. aureus isolates resistant to macrolides in 2013, 2016, and 2019 was statistically significantly higher in Poltava region. In other years (except 2014) statistically significant differences were found to be in favour of a higher resistance of S. aureus isolates in Kharkiv region (Fig. 2a). Generally, during the period from 2013 to 2019, the proportion of S. aureus strains resistant to the macrolides group medications was slightly higher (1.1 times) in Kharkiv region $(19.9 \% / \mathrm{n}=1,522$ of 7,642 versus $18.1 \% / \mathrm{n}=1,827$ of 10,$\left.092 ; \chi^{2}=9.3 ; \mathrm{P}=0.002\right)$.

In Kharkiv region, the largest proportion of $S$. aureus strains resistant to lincozamids was identified in 2015, and the smallest - in $2013(41.6 \%$ and $3.1 \%$ respectively). In Poltava region more than half of the identified S. aureus strains in 2014 (54.0\%) were resistant to lincozamids group antibiotics. The lowest resistance to lincozamids in Poltava region was in S. aureus strains identified in 2015 (10.0\%). Statistically significant differences in proportion of $S$. aureus strains resistant to lincozamids in the compared regions were found in 2013-2015 and in 2017-2019 (Fig. 2b). On the whole, during the analyzed period 1.9 times more $S$. aureus isolates resistant to lincozamids were identified in Poltava region than in Kharkiv region $(16.3 \% / \mathrm{n}=1,436$ of 8,792 versus $8.5 \% / \mathrm{n}=864$ of 10,$\left.156 ; \chi^{2}=270.6 ; \mathrm{P}<0.001\right)$.

The proportion of $S$. aureus isolates resistant to the tetracycline medications group in Kharkiv region varied within $0.6 \%$ in 2013 to $15.3 \%$ in 2016. The proportion of tetracycline resistant $S$. aureus strains in Poltava region reached its maximum in 2019 , amounting to $30.5 \%$. The smallest proportion of the resistant isolates in Poltava region was identified in 2015 (9.1\%). The statistically significant differences between the proportion of tetracycline-resistant $S$. aureus isolates in the compared regions were identified in 2013, 2014, and 2016-2019 (Fig. 2c). On the whole, during the studied period, the proportion of $S$. aureus strains resistant to tetracycline antibiotics was 1.9 times higher in Poltava region $(15.7 \% / \mathrm{n}=1,560$ of 9,934 versus $8.3 \% / \mathrm{n}=294$ of 3,$\left.534 ; \chi^{2}=119.7 ; \mathrm{P}<0.001\right)$.

In Kharkiv region in 2013 and 2014, 96.3\% and $89.1 \%$ isolated S. aureus strains respectively were resistant to vancomycin. The smallest amount of $S$. aureus strains resistant to vancomycin in Kharkiv region was identified in $2016(0.6 \%)$. In Poltava region, of the 1063 S. aureus isolates studied in 2017, none was resistant to vancomycin. Nevertheless, more than the quarter of the identified isolates in $2019(26.6 \%)$ in Poltava region were resistant to this antibiotic. In 2013, 2014 and 2017, the proportion of $S$. aureus isolates resistant to vancomycin was statistically significantly higher $(\mathrm{P}<0.001)$ in Kharkiv region (Fig. 3a).

Using Fisher's exact test, we found statistically significant differences in proportion of rifampicin resistant isolates of $S$. aureus in the compared regions in 2013, 2014 and $2016(\mathrm{P}<0.05)$. The proportion of rifampicinresistant isolates of $S$. aureus in the Poltava region was higher. It should be noted that during the whole studied period, the proportion of rifampicinresistant $S$. aureus isolates in Kharkiv region did not exceed 7.8\% $(\mathrm{n}=19$ of 244 in 2017), and in Poltava region it did not exceed $11.6 \%$ ( $n=11$ of 95 in 2016).

Comparative analysis by the regions of resistance of $S$. aureus isolates to fluoroquinolones medications showed that in Poltava region the proportion of resistant strains prevailed over that of Kharkiv region during the whole period of observation except 2017 (Fig. 3b). In Poltava region, the proportion of the resistant strains varied between $15.6 \%$ in 2014 and $24.5 \%$ in 2019 . In Kharkiv region, the proportion of the resistant isolates was between $3.0 \%$ in 2013 and $26.9 \%$ in 2017 . Overall, during the studied period, the proportion of fluoroquinolone resistant $S$. aureus strains was 3.3 times higher in Poltava region $(19.7 \% / \mathrm{n}=3,110$ of 15,771 versus $5.9 \% / \mathrm{n}=1995$ of 3,$\left.3619 ; \chi^{2}=2201.3 ; \mathrm{P}<0.001\right)$. 
The analysis of $S$. aureus strains resistant to linezolid has demonstrated that in Poltava region the proportion of resistant microorganisms was statistically significantly higher in 2013-2014 and 2016-2018 (Fig. 3c). Notably, in Kharkiv region linezolid-resistant strains accounted for $19.3 \%$ of antibiotic resistant strains identified in 2015, which exceeded by $8.5 \%$ the maximum proportion of linezolid-resistant strains of S. aureus identi- fied in Poltava region. Due to the small number of co-trimoxazol sensitivity tests $(\mathrm{n}=14)$ of $S$. aureus made in Kharkiv region, it is impossible to interpret correctly the negative results obtained. Nevertheless, more tests were made in Poltava region, and the proportion of resistant isolates varied there between $3.4 \%(n=9$ of 268$)$ in 2019 and $43.7 \%(n=52$ of 119$)$ in 2016.
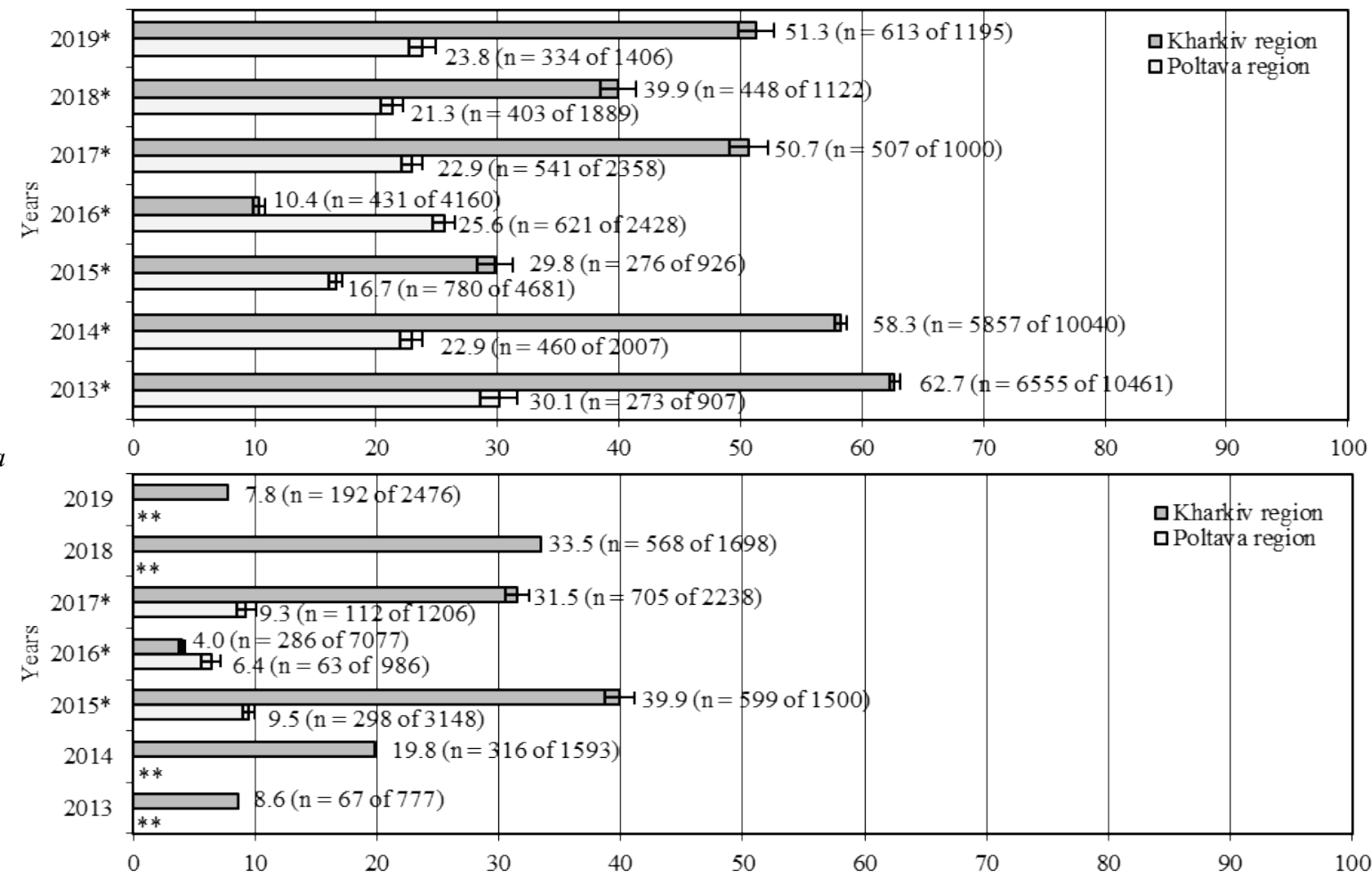

$b$
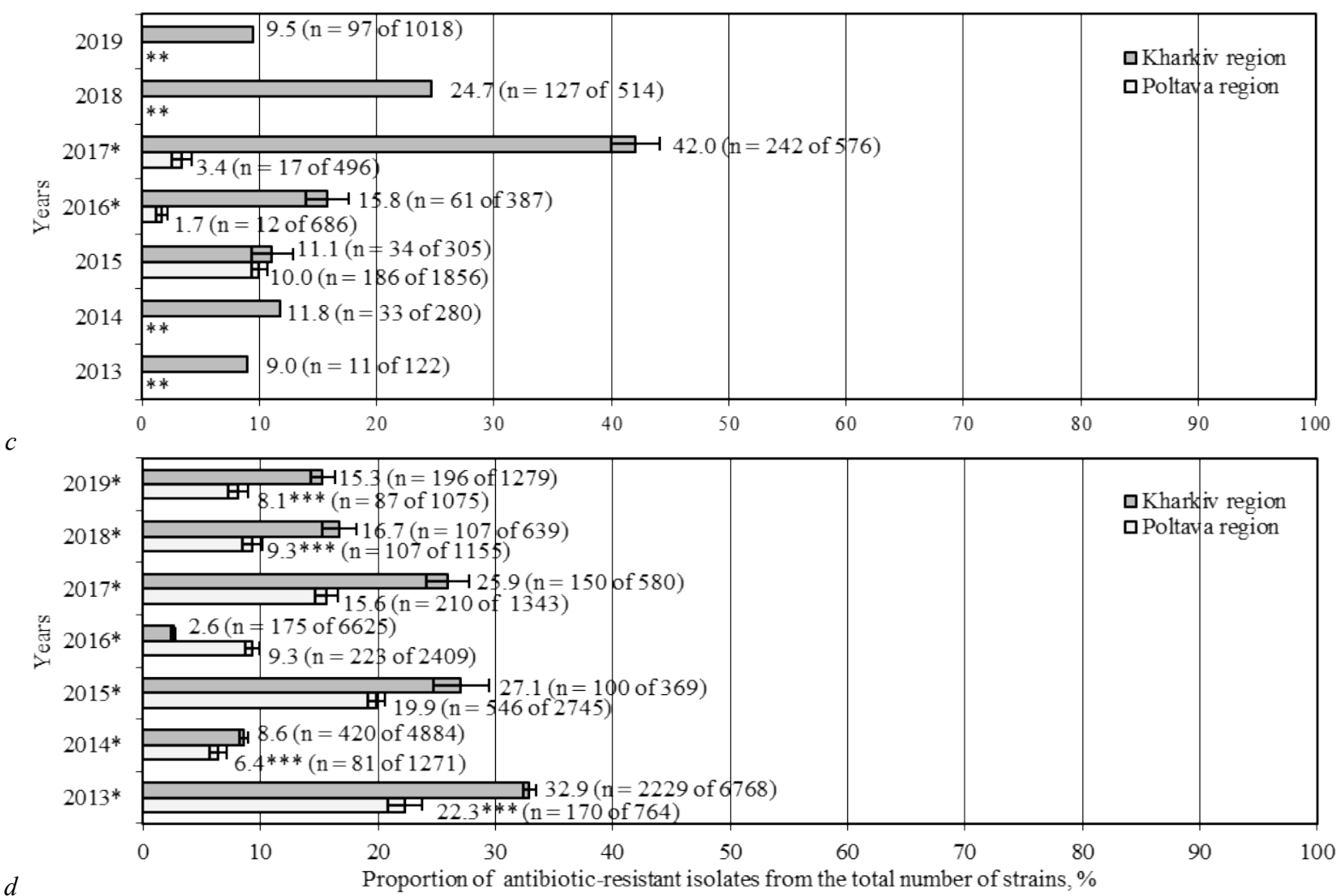

Fig. 1. Proportion ( $\mathrm{x} \pm \mathrm{SE}, \%)$ of penicillin antibiotics-resistant (a), cephalosporin antibiotics-resistant $(b)$, carbapenem antibiotics-resistant $(c)$, aminoglycoside antibiotics-resistant $(d)$ strains of $S$. aureus in Kharkiv and Poltava regions during 2013-2019: * - the differences are statistically significant at $\mathrm{P}<0.01,{ }^{* *}$ - antibiotic resistance was not studied in Poltava region that year, *** - there are available data on resistance to only one amiglycoside antibiotic (gentamycin) 


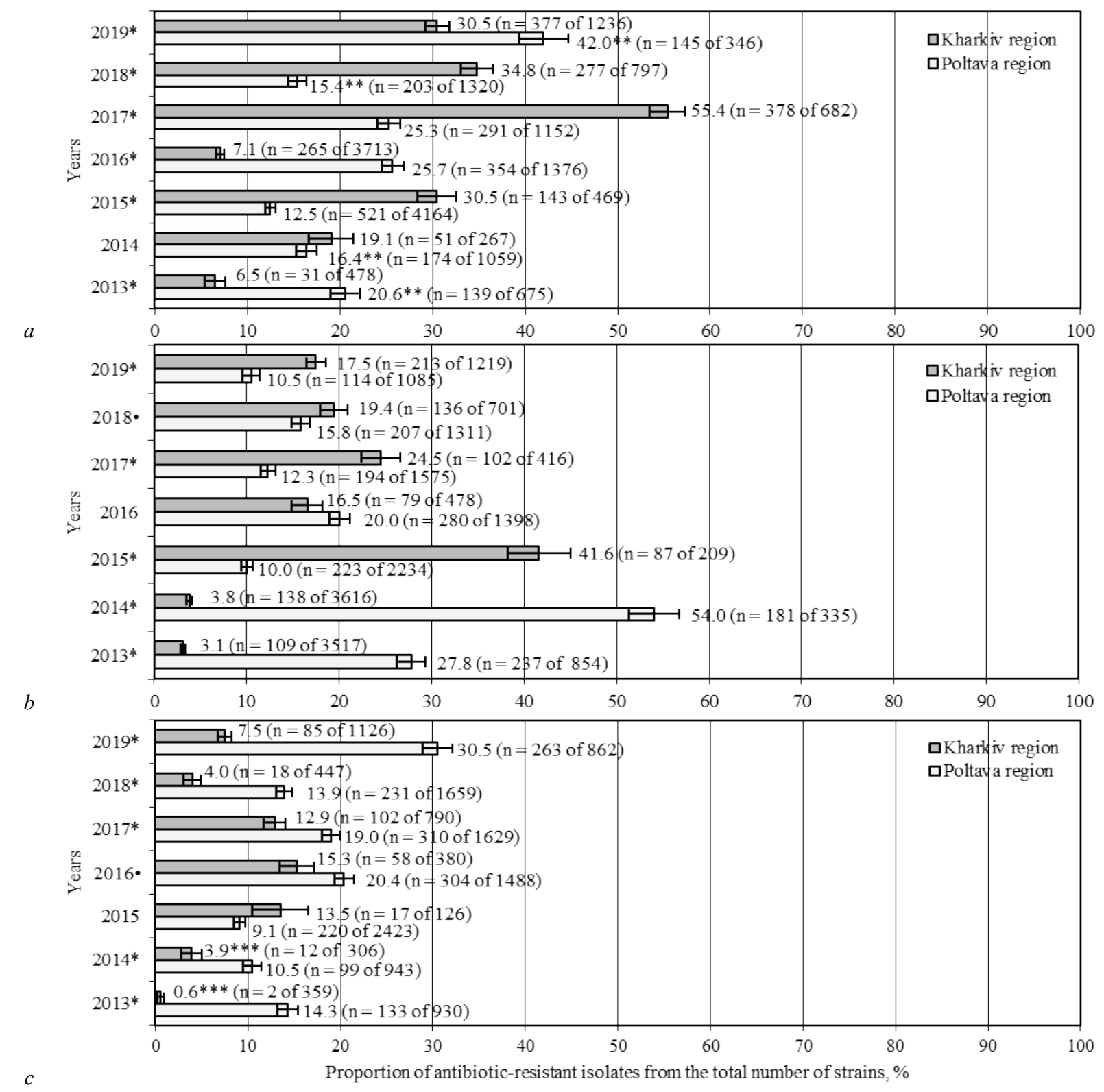

Fig. 2. Proportion ( $\mathrm{x} \pm \mathrm{SE}, \%)$ of macrolide antibiotics-resistant $(a)$, lincozamid antibiotics-resistant $(b)$, tetracycline antibiotics-resistant $(c)$, strains of S. aureus in Kharkiv and Poltava regions during 2013-2019: * - the differences are statistically significant at $\mathrm{P}<0.01$,

- -the differences are statistically significant at $\mathrm{P}<0.05,{ }^{* *}$ - there are available data on resistance to only one macrolide antibiotic (erythromycin), $* * *$ - there are available data on resistance to only one tetracycline antibiotic (tetracycline)

The largest proportion of $S$. aureus isolates resistant to chloramphenicol was identified in Kharkiv region in 2018 (60.4\%), and in Poltava region - in 2014 (63.6\%). In 2016-2019, the differences in both regions were statistically significant (Fig. 3d). During the period of 2014-2015 and in 2017, in Poltava region 9.2\% $(\mathrm{n}=27$ of 293$)$ of $S$. aureus isolates were found to be resistant to phosphomycin. $8.2 \%(\mathrm{n}=18$ of 220$)$ of $S$. aureus strains were found to be resistant to fusidic acid in Poltava region in 20162018. Also, in 2015-2016 and in 2018 in Poltava region, 41.4\% $(n=137$ of 331) of S. aureus isolates were identified as resistant to nitrofuran derivatives. The analysis of S. epidermidis isolates' resistance has demonstrated that in Kharkiv region in 2015 , nearly half $(47.6 \%)$ of the isolates were found to be resistant to the penicillin antibiotics (Fig. 4).

Notably, from 2012 to 2015 among the S. epidermidis isolates there was a growth in the prevalence of resistance to cephalosporins, aminoglycosides, macrolides, and fluoroquinolones. When determining the carbapenems resistance in $2013,3.1 \%(\mathrm{n}=1$ of 32$)$ of $S$. epidermidis were found to be resistant to imipenem. In 2014 and 2015, the proportion of the carbapenems-resistant strains was considerably larger, $15.5 \%(\mathrm{n}=25$ of $161)$ and $16.3 \%(n=33$ of 203) respectively. In 2013, sensitivity in 11 strains of $S$. epidermidis to aztreonam was determined. In three cases, the isolates were resistant. In 2013 and 2014, relatively few lincozamid-resistant isolates were identified: $1.7 \%(\mathrm{n}=8$ of 470$)$ and $5.5 \%(\mathrm{n}=16$ of 289$)$ respectively. In 2015, sensitivity to clindamycin was identified in 13 S. epidermidis strains. In four cases, the isolates were resistant. The proportion of tetracycline-resistant isolates in 2013 comprised $4.2 \%(n=9$ of 213 ), in $2014-4.9 \%(\mathrm{n}=11$ of 223$)$. When analyzing $S$. epidermidis resistance to vancomycin, a decrease in the proportion of resistant strains from $88.0 \%$ in 2013 to $8.7 \%$ in 2015 was noted. The resistance of S. epidermidis isolates to rifampicin was studied only in 2013 and 2014. The proportion of the resistant strains was $3.7 \%(n=8$ of 214$)$ and $8.7 \%(n=2$ of 23$)$ respectively. In 2015, the proportion of linezolid-resistant strains grew sharply. In 2015 , sensitivity to chloramphenicol was identified in 28 S. epidermidis strains. In 24 cases (85.7\%), the isolates were resistant.

\section{Discussion}

The study has confirmed the existence of differences in the prevalence of S. aureus isolates resistant to various groups of antibacterial medications in Kharkiv and Poltava regions. In Kharkiv region, strains resistant to medications of penicillin group, cephalosporins, carbapenems, amino- 
glycosides, and macrolides were identified more often than in Poltava region. In Poltava region, strains resistant to lincozamids, tetracycline antibiotics, and fluoroquinolones were identified more often than in Kharkiv region. This can be ascribed to the regional peculiarities in antibiotics consumption by the population and in medical practices. A high occurrence of $S$. aureus isolates resistant to natural and some synthetic and semisynthetic penicillin antibiotics (penicillin, ampicillin) is confirmed by other authors' studies (Deyno et al., 2017; Y1lmaz \& Aslantaş, 2017). Inhibitor-protected penicillins still remain quite efficient, although the high adaptability of $S$. aureus can make antibiotics of this group totally inefficient rather soon.

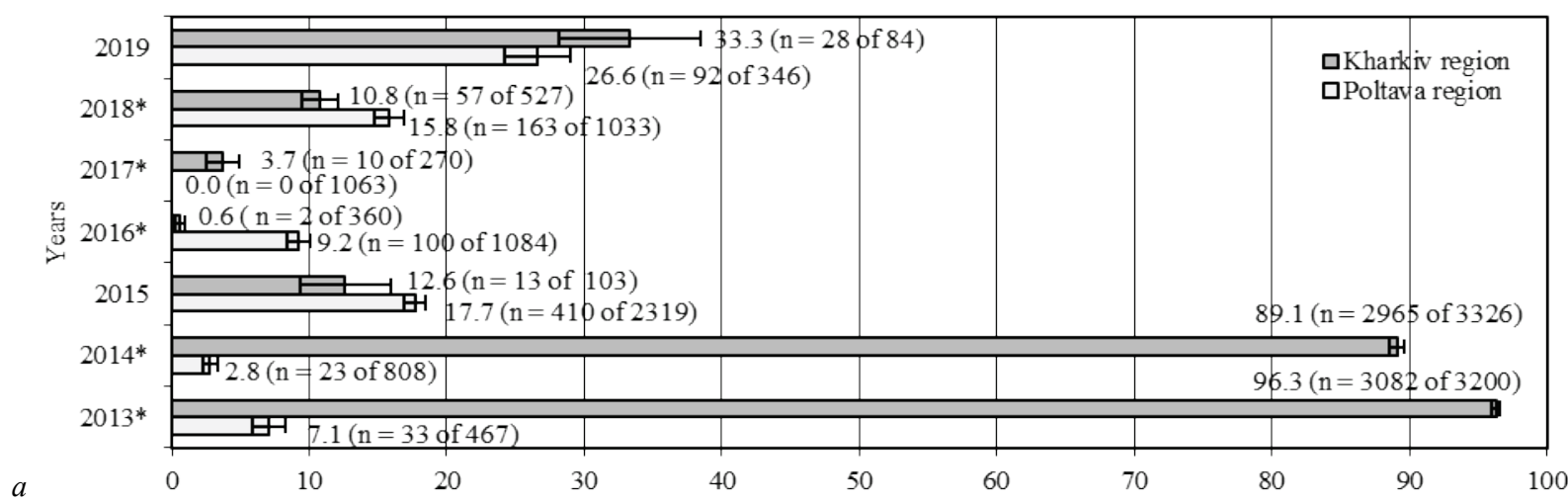

$a$

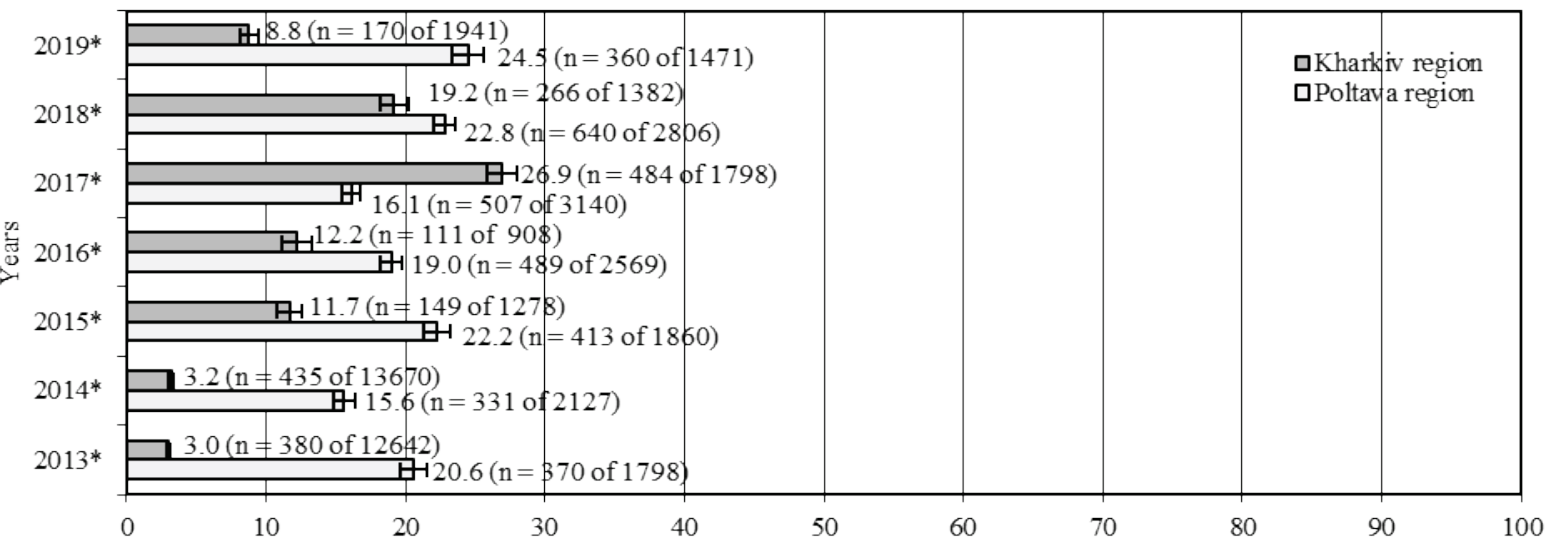

$b$
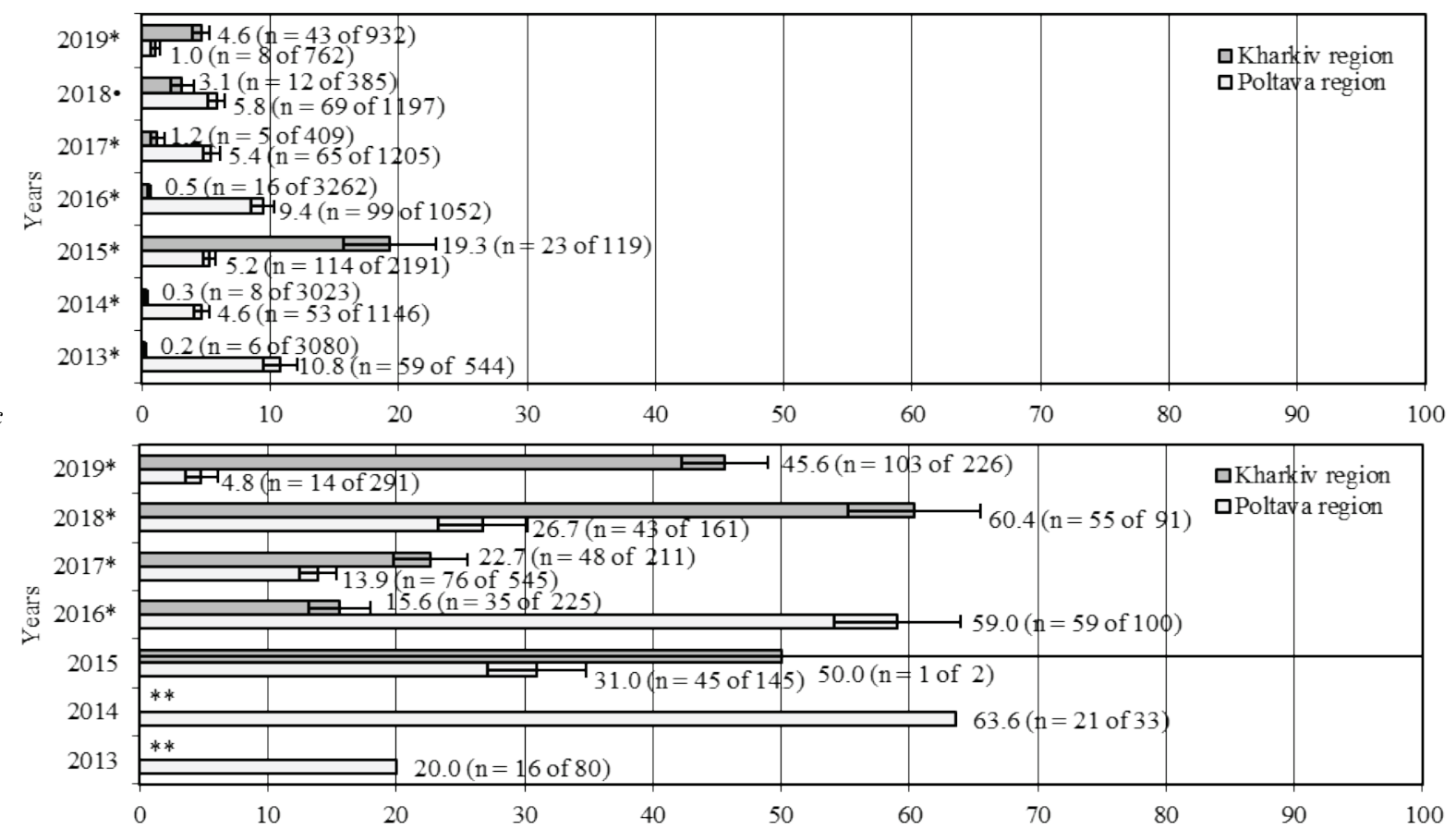

$d$

Proportion of antibiotic-resistant isolates from the total number of strains, \%

Fig. 3. Proportion ( $\mathrm{x} \pm \mathrm{SE}, \%$ ) of vancomycin-resistant $(a)$, fluoroquinolones-resistant $(b)$, linezolid-resistant $(c)$, chloramphenicol-resistant $(d)$ strains of $S$. aureus in Kharkiv and Poltava regions during 2013-2019: * - the differences are statistically significant at $\mathrm{P}<0.01$, - - the differences are statistically significant at $\mathrm{P}<0.05,{ }^{* *}$ - antibiotic resistance was not studied in Kharkiv region in this year

We noted that in Poltava region, the proportion of $S$. aureus isolates resistant to cephalosporins and carbapenems is relatively low. The monitoring of resistance to these antibiotics groups in Poltava region is not conducted on a regular basis. In Kharkiv region, the largest proportion of strains resistant to cephalosporins and carbapenems medications amounted to $39.9 \%$ and $42.0 \%$ respectively. Therefore, Poltava region also needs to monitor on a regular basis the resistance of $S$. aureus to these groups of medications and to apply them in treatment protocols with care. 


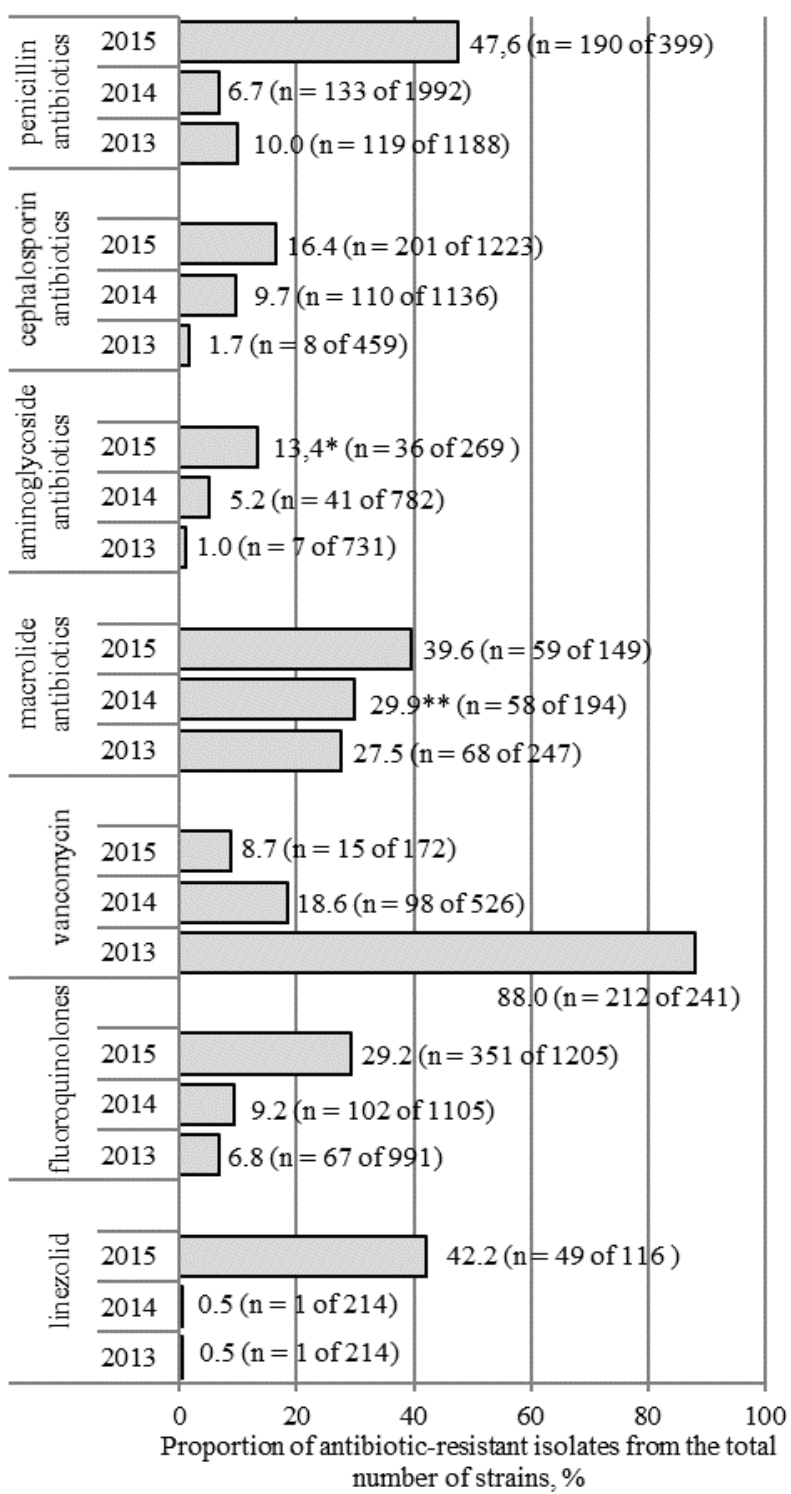

Fig. 4. Proportion (\%) of antibiotic-resistant strains of S. epidermidis in Kharkiv region during 2013-2015: * - there are available data on resistance to only one amiglycoside antibiotic (amikacin),

** - there are available data on resistance to only one macrolide antibiotic (erythromycin)

Hauschild et al. (2008) reported that $38.1 \%$ of $S$. aureus isolates in their study were resistant to at least one antibiotic of the aminoglycoside group. In the present study, the aminoglycoside resistance in both regions was generally much lower. In comparison with the work by Liu et al. (2017), the authors identified a high resistance in S. aureus isolates to the macrolides group. Also, the authors have identified a generally lower resistance in $S$. aureus isolates to the tetracycline group medications than Ullah et al. (2013).

It is considered that resistance in S. aureus to fluoroquinolones is formed as a result of treating illnesses caused by other agents when the skin of the hands and mucous coverings of a person receiving medications of this group are colonized by S. aureus. In that case, S. aureus is influenced by sub-therapeutic concentrations of drugs, which may cause mutations (Lowy, 2003). In the our study, fluoroquinolone-resistant S. aureus strains were identified in some years in a quarter of cases. Therefore, departing from the resistance formation mechanism, prescribing of any antibacterial medication should be duly substantiated.

In comparison with the study by Rağbetli et al. (2016), we have identified a high resistance to linezolid ( $0 \%$ of resistant strains according to their data versus $19.3 \%$ of resistant strains identified in 2015 in Kharkiv region in our study). Linezolid is an antibiotic which is efficient against gram-positive flora including metycillin-resistant staphylococci (Gu et al.,
2012), therefore the results obtained by us in this study call for further study and identifying the causes of such a high resistance.

Similar data (compared with Poltava region) concerning S. aureus resistance to co-trimoxazol were demonstrated by Deyno et al. (2017). Due to the insufficient amount of tests in Kharkiv region, we think that it is necessary to continue studying the sensitivity to co-trimaxazol in Kharkiv region to find out whether there are any territorial differences in S. aureus resistance to this antibiotic.

When analyzing the dynamics of prevalence of resistant $S$. aureus strains in the regions, we found a broad difference in the proportion of isolates resistant to some antibiotics. For instance, in Kharkiv region, 96.3\% of S. aureus isolates were found to be vancomycin-resistant in 2013, while in 2016 - less than 1\%. Also in Kharkiv region, 3.1\% of strains were found to be resistant to the lincozamid group in 2013, while in 2015 $41.6 \%$. These results can be probably ascribed to the disproportional amount of cultures sampled in healthcare settings for our study. This indicate that every healthcare setting has unique microbiological profile.

The research by Mohaghegh et al. (2015) has demonstrated efficiency in using chloramphenicol against $S$. aureus isolates sampled from the patients with suspected bacteremia. In our study, the proportion of chloramphenicol-resistant isolates was high in both regions in certain years. In view of this, we think that the study of $S$. aureus sensitivity to this medication should be continued by increasing the number of the studied isolates.

As to $S$. epidermidis, it should be noted that despite its long since proven pathogenicity (Morgunov \& Kukharchik, 1986), this microorganism is still underestimated in medical practice as being a cause of a number of infections. At the same time, S. epidermidis possesses properties and mechanisms owing to which it manages to fix itself on the human body and avoid being destroyed by the immune system. Normally, owing to its adhesive properties, S. epidermidis fixes itself to the host's proteins in the skin, and in cases of damage, wounds, introduction of foreign bodies (prosthetics, vessels catheterization), the infectious agent fixes itself to deeper-laying tissues or to the surface of the implanted appliances (Sabaté Brescó et al., 2017).

The analyses on determining $S$. epidermidis strains resistance to antibiotics made in Kharkiv region show in the dynamics a rise in the proportion of isolates resistant to most of the antibiotics groups: to penicillins, cephalosporins, aminoglycosides, macrolides, and fluoroquinolones. As early as in 1980, Archer \& Tenenbaum in their study on patients surviving heart operations reported a high proportion of $S$. epidermidis isolates resistant to naphycillin, penicillin (100\% each), to cephalotin ( $93 \%)$, to cephamandol $(80 \%)$, to streptomycin $(67 \%)$. Other researchers report the high prevalence of resistance in hospital $S$. epidermidis strains to many medications: to penicillin, cefazolin, tetracycline, erythromycin. Moreover, in the isolated strains simultaneous resistance to more than three groups of antibiotics was observed, and in $17.4 \%$ - to seven different groups of antibiotics (Chabi \& Momtaz, 2019). Of great concern is the high proportion of vancomycin-resistant $S$. epidermidis strains isolated in Kharkiv region in 2013. Nunes et al. (2016) state that the resistance in S. epidermidis strains to glycopeptide antibiotics is influenced by the thickness of the cell's membrane. Also, the authors report the heterogenic resistance of S. epidermidis to glycopeptides. At the same time, in another study, vancomycin is viewed as the most efficient medicine against $S$. epidermidis for treating patients with suspected bacteremia (Mohaghegh et al., 2015). Chabi \& Momtaz (2019) also reported the high prevalence of S. epidermidis resistance to co-trimaxazol. Because in the present study we did not identify resistance to this medication, it should be accounted for in further studies. Therefore, considering the aforementioned, the study of resistance of S. epidermidis isolates should be obligatory all over the country without limitation to individual regions. Our study demonstrates that in Ukraine there is a need for the introduction of a complex approach to the issue of antibiotics resistance. Epidemiological monitoring of hospital infectious agents should be strengthened at the national level, and in the regions, the scope of conducted bacteriological researches should be broadened with further identification of antibiotic sensitivity in the isolated strains. It is also necessary to identify in the isolated microorganisms the ability to form biofilms and the traits of their biofilm forms. Additional introduction of moleculargenetic methods, identifying hetero-resistance in microorganisms and the study of their subpopulations can help the patients whose treatment does 
not fit into standard procedures and ensure an individual approach to every patient within personalized healthcare.

The territorial differences in antibiotic resistance of $S$. aureus isolates disclosed in the present study attest to the expediency in maintaining microbiological monitoring both on the regional level and the institutional level. Considering the growing resistance in S. epidermidis isolates to penicillins, cephalosporins, aminoglycosides, macrolides, and fluoroquinolones identified in Kharkiv region, obligatory assessment of sensitivity of this genus of microorganisms to antibacterial medication should be conducted on a regular basis at healthcare settings of both Kharkiv region and other districts and regions. Forming the unified national data network on microorganism resistance in regions will become the foundation for developing strategies on infection control and prevention of cases of infection associated with rendering of health-care aid, including prevention of catheter-related bloodstream infections. Considering the available data on resistance in hospital strains of microorganisms, it is necessary to develop new and improve the acting local protocols of patients' antibiotic treatment. Rational and scientifically substantiated application of antibiotic medications in medical practices will enable efficient prevention of formation of microorganism-resistant strains, which will raise the quality of health-care aid rendered to the population, decrease the number of complications, and diminish economic losses caused by infections associated with resistant microorganisms.

\section{Conclusion}

We identified peculiarities in antibiotic resistance patterns in regions of Ukraine. In total, the proportion of $S$. aureus strains resistant to penicillins, cephalosporins, carbapenems, aminoglycosides, and macrolides was higher in Kharkiv region in terms of statistical validity than in Poltava region. Overall, the proportion of $S$. aureus strains resistant to lincozamids, tetracycline antibiotics, and fluoroquinolones in Poltava region was higher in terms of statistical validity than in Kharkiv region. Assessment of antibiotic resistance in S. epidermidis isolates in Kharkiv region showed increase in resistance to the most antibiotics (penicillins, cephalosporins, aminoglycosides, macrolides, and fluoroquinolones).

Further studies are needed to create of passports of microorganism resistance in the regions and medical institutions, as well as to create a unified national database network on microorganism resistance using modern methodologies of determining the phenotypes and genotypes of microorganisms.

The authors would like to express their express their sincere gratitude to the SI Kharkiv Oblast Laboratory Center of the MoH of Ukraine and to SI Poltava Oblast Laboratory Center of the $\mathrm{MoH}$ of Ukraine for their assistance in conducting this study.

The study has been performed within the framework of the science-and-research work Epidemiology Department of Kharkiv National Medical University titled "To develop a scientifically substantiated strategy of prevention of antibiotic resistance of bacteria causing healthcare-associated infections in healthcare facilities" (State Registration No 0118U000944).

\section{References}

Aghdassi, S., Schröder, C., Gruhl, D., Gastmeier, P., \& Salm, F. (2019). Point prevalence survey of peripheral venous catheter usage in a large tertiary care university hospital in Germany. Antimicrobial Resistance and Infection Control, 8(1), 15.

Archer, G., \& Tenenbaum, M. (1980). Antibiotic-resistant Staphylococcus epidermidis in patients undergoing cardiac surgery. Antimicrobial Agents and Chemotherapy, 17(2), 269-272.

Bauer, A., Kirby, W., Sherris, J., \& Turck, M. (1966). Antibiotic susceptibility testing by a standardized single disk method. American Journal of Clinical Pathology, 45(4), 493-496.

Brown, A., Leech, J., Rogers, T., \& McLoughlin, R. (2014). Staphylococcus aureus colonization: Modulation of host immune response and impact on human vaccine design. Frontiers in Immunology, 4, 507.

Brusselaers, N., Vogelaers, D., \& Blot, S. (2011). The rising problem of antimicrobial resistance in the intensive care unit. Annals of Intensive Care, 1(1), 47.

Canadian Nosocomial Infection Surveillance Program (2020). Healthcare-associated infections and antimicrobial resistance in Canadian acute care hospitals, 2014 2018. Canada Communicable Disease Report, 46(5), 99-112.
Chabi, R., \& Momtaz, H. (2019). Virulence factors and antibiotic resistance properties of the Staphylococcus epidermidis strains isolated from hospital infections in Ahvaz, Iran. Tropical Medicine and Health, 47(1), 56.

Cherifi, S., Byl, B., Deplano, A., Nagant, C., Nonhoff, C., Denis, O., \& Hallin, M. (2014). Genetic characteristics and antimicrobial resistance of Staphylococcus epidermidis isolates from patients with catheter-related bloodstream infections and from colonized healthcare workers in a Belgian hospital. Annals of Clinical Microbiology and Antimicrobials, 13(1), 20

Clinical and Laboratory Standards Institute (2014). Performance standards for antimicrobial susceptibility testing; twenty-fourth informational supplement. CLSI document M100-S24. Wayne, Pennsylvania.

Conlan, S., Mijares, L., NISC Comparative Sequencing Program, Becker, J., Blakesley, R., Bouffard, G., Brooks, S., Coleman, H., Gupta, J., Gurson, N., Park, M., Schmidt, B., Thomas, P., Otto, M., Kong, H., Murray, P., \& Segre, J. (2012). Staphylococcus epidermidis pan-genome sequence analysis reveals diversity of skin commensal and hospital infection-associated isolates. Genome Biology, 13(7), R64.

Costerton, J., Montanaro, L., \& Arciola, C. (2005). Biofilm in implant infections: Its production and regulation. The International Journal of Artificial Organs, 28(11), 1062-1068.

Deurenberg, R., \& Stobberingh, E. (2008). The evolution of Staphylococcus aureus. Infection, Genetics and Evolution, 8(6), 747-763.

Deurenberg, R., Vink, C., Kalenic, S., Friedrich, A., Bruggeman, C., \& Stobberingh, E. (2007). The molecular evolution of methicillin-resistant Staphylococcus aureus. Clinical Microbiology and Infection, 13(3), 222-235.

Du, X., Zhu, Y., Song, Y., Li, T., Luo, T., Sun, G., Yang, C., Cao, C., Lu, Y., \& Li, M. (2013). Molecular analysis of Staphylococcus epidermidis strains isolated from community and hospital environments in China. PloS One, 8(5), e62742.

Gu, B., Kelesidis, T., Tsiodras, S., Hindler, J., \& Humphries, R. (2012). The emerging problem of linezolid-resistant Staphylococcus. Journal of Antimicrobial Chemotherapy, 68(1), 4-11.

Guembe, M., Pérez-Granda, M. J., Capdevila, J. A., Barberán, J., Pinilla, B., MartínRabadán, P., Bouza, E., on behalf of the NUVE Study Group, Millán, J., Pérez de Oteyza, C., Muiño, A., Villalba, M., Cuenca, C., Castaño, J. G., Delgado, C. M., Zamorano, S., Gómez, B., Collado, J. M., Salinas, M. T, Amat, A. S., Lázaro, J. R., Sordo, V. V., Sánchez, M. V., Benach, Á. F., Vidal, E., Albiach, L., Aparicio, J. M. A., Arroniz, E. S. A., Casademont, I., Pou, J., Solchaga, V. P., Castellón, F. E., Obanos, T. R., Egurbide Arberas, M. V., Arana, J. N., López, E. G., Gaviria, A. Z., Clemente, I. N., Ruíz, P. C., Salomó, A. C., Iftimie, S. M., Castillo, A. M., Barberá Farré, J. R., Lavería, A. O., Ribera, M. C., Pallarés, N. B., Suárez, P. C., Piomo, F. J. C., Andrés, N. A., Tarazona, R. E. R., Zapata, M. M. R., \& Cerdá, M. A. C. (2017). Nationwide study on peripheral-venouscatheter-associated-bloodstream infections in internal medicine departments. Journal of Hospital Infection, 97(3), 260-266.

Hauschild, T., Sacha, P., Wieczorek, P., Zalewska, M., Kaczyńska, K., \& Tryniszewska, E. (2008). Aminoglycosides resistance in clinical isolates of Staphylococcus aureus from a University Hospital in Bialystok, Poland. Folia Histochemica et Cytobiologica, 46(2), 225-228.

Hellmark, B., Söderquist, B., Unemo, M., \& Nilsdotter-Augustinsson, Å. (2013). Comparison of Staphylococcus epidermidis isolated from prosthetic joint infections and commensal isolates in regard to antibiotic susceptibility, agr type, biofilm production, and epidemiology. International Journal of Medical Microbiology, 303(1), 32-39.

Jokinen, E., Laine, J., Huttunen, R., Rahikka, P., Huhtala, H., Vuento, R., Vuopio, J., \& Syrjänen, J. (2017). Comparison of outcome and clinical characteristics of bacteremia caused by methicillin-resistant, penicillin-resistant and penicillinsusceptible Staphylococcus aureus strains. Infectious Diseases, 49(7), 493-500.

Kaplan, J. (2011). Antibiotic-induced biofilm formation. International Journal of Artificial Organs, 34(9), 737-751.

Kollef, M., \& Fraser, V. (2001). Antibiotic resistance in the intensive care unit. Annals of Internal Medicine, 134(4), 298-314.

Lindsay, J. (2010). Genomic variation and evolution of Staphylococcus aureus. International Journal of Medical Microbiology, 300(2-3), 98-103.

Liu, X., Deng, S., Huang, J., Huang, Y., Zhang, Y., Yan, Q., Wang, Y., Li, Y., Sun, C., \& Jia, X. (2017). Dissemination of macrolides, fusidic acid and mupirocin resistance among Staphylococcus aureus clinical isolates. Oncotarget, 8(35), 58086-58097.

Lowy, F. (2003). Antimicrobial resistance: The example of Staphylococcus aureus. Journal of Clinical Investigation, 111(9), 1265-1273.

Manandhar, S., Singh, A., Varma, A., Pandey, S., \& Shrivastava, N. (2018). Biofilm producing clinical Staphylococcus aureus isolates augmented prevalence of antibiotic resistant cases in tertiary care hospitals of Nepal. Frontiers in Microbiology, 9, 2749 .

Mandolfo, S., Anesi, A., Maggio, M., Rognoni, V., Galli, F., \& Forneris, G. (2019). High success rate in salvage of catheter-related bloodstream infections due to Staphylococcus aureus, on behalf of project group of Italian society of nephrology. The Journal of Vascular Access, 21(3), 336-341. 
Mermel, L. (2017). Short-term peripheral venous catheter-related bloodstream infections: A systematic review. Clinical Infectious Diseases, 65(10), 1757-1762.

Mohaghegh, M., Ghazvini, K., Jafari, R., Alikhani, M., Safari, M., Azari Garamjan, G., Falahi, J., \& Bordbar, D. (2015). Retrospective study on the prevalence and antibiotic resistance pattern of Staphylococcus aureus and Staphylococcus epidermidis among patients suspicious of bacteremia during 2006-2011. International Journal of Enteric Pathogens, 3(2), e22930.

Morgunov, I. N., \& Kukharchik, T. A. (1986). Immunologicheskie kriterii patogennosti epidermal'nogo stafilokokka [Immunological criteria of the pathogenicity of epidermal Staphylococcus]. Mikrobiologicheskii Zhurnal, 48(5), 32-35 (in Russian).

Nguyen, D. B., Shugart, A., Lines, C., Shah, A. B., Edwards, J., Pollock, D., Sievert, D., \& Patel, P. R. (2017). National Healthcare Safety Network (NHSN) dialysis event surveillance report for 2014. Clinical Journal of the American Society of Nephrology, 12(7), 1139-1146.

Nunes, A., Teixeira, L., Iorio, N., Bastos, C., Fonseca, L., Soutopadron, T., \& Dossantos, K. (2006). Heterogeneous resistance to vancomycin in Staphylococcus epidermidis, Staphylococcus haemolyticus and Staphylococcus warneri clinical strains: Characterisation of glycopeptide susceptibility profiles and cell wall thickening. International Joumal of Antimicrobial Agents, 27(4), 307-315.

Rağbetli, C., Parlak, M., Bayram, Y., Guducuoglu, H., \& Ceylan, N. (2016). Evaluation of antimicrobial resistance in Staphylococcus aureus isolates by years. Interdisciplinary Perspectives on Infectious Diseases, 2016, 9171395.

Sabaté Brescó, M., Harris, L., Thompson, K., Stanic, B., Morgenstern, M., O’Mahony, L., Richards, R., \& Moriarty, T. (2017). Pathogenic mechanisms and host interactions in Staphylococcus epidermidis device-related infection. Frontiers in Microbiology, 8, 1401.

Saharman, Y., Karuniawati, A., Severin, J., \& Verbrugh, H. (2021). Infections and antimicrobial resistance in intensive care units in lower-middle income countries: A scoping review. Antimicrobial Resistance and Infection Control, 10(1), 22.

Sharma, A., Kalita, J., \& Nag, V. (2019). Screening for methicillin-resistant Staphylococcus aureus carriage on the hands of healthcare workers: an assessment for hand hygiene practices. Indian Journal of Critical Care Medicine, 23(12), 590-592.
Smith, R. N., \& Nolan, J. P. (2013). Central venous catheters. The British Medical Journal, 347(11), f6570.

Tatsuno, K., Ikeda, M., Wakabayashi, Y., Yanagimoto, S., Okugawa, S., \& Moriya, K. (2019). Clinical features of bloodstream infections associated with peripheral versus central venous catheters. Infectious Diseases and Therapy, 8(3), 343-352.

Torumkuney, D., Pertseva, T., Bratus, E., Dziublik, A., Yachnyk, V., Liskova, A., Sopko, O., Malynovska, K., \& Morrissey, I. (2018). Results from the survey of antibiotic resistance (SOAR) 2014-16 in Ukraine and the Slovak Republic. Journal of Antimicrobial Chemotherapy, 73(suppl. 5), v28-v35.

Ullah, F., Malik, S., Ahmed, J., Ullah, F., Shah, S., Ayaz, M., Hussain, S., \& Khatoon, L. (2013). Investigation of the genetic basis of tetracycline resistance in Staphylococcus aureus from Pakistan. Tropical Joumal of Pharmaceutical Research, 11(6), 925-931.

Voidazan, S., Albu, S., Toth, R., Grigorescu, B., Rachita, A., \& Moldovan, I. (2020). Healthcare associated infections - a new pathology in medical practice? International Joumal of Environmental Research and Public Health, 17(3), 760.

Wertheim, H., Melles, D., Vos, M., Van Leeuwen, W., Van Belkum, A., Verbrugh, H., \& Nouwen, J. (2005). The role of nasal carriage in Staphylococcus aureus infections. The Lancet Infectious Diseases, 5(12), 751-762.

Widerström, M., Wiström, J., Edebro, H., Marklund, E., Backman, M., Lindqvist, P., \& Monsen, T. (2016). Colonization of patients, healthcare workers, and the environment with healthcare-associated Staphylococcus epidermidis genotypes in an intensive care unit: A prospective observational cohort study. BMC Infectious Diseases, 16(1), 743.

Wu, J., Kusuma, C., Mond, J., \& Kokai-Kun, J. (2003). Lysostaphin disrupts Staphylococcus aureus and Staphylococcus epidermidis biofilms on artificial surfaces. Antimicrobial Agents and Chemotherapy, 47(11), 3407-3414.

Yılmaz, E., \& Aslantaş, Ö. (2017). Antimicrobial resistance and underlying mechanisms in Staphylococcus aureus isolates. Asian Pacific Joumal of Tropical Medicine, 10(11), 1059-1064.

Zhang, L., Cao, S., Marsh, N., Ray-Barruel, G., Flynn, J., Larsen, E., \& Rickard, C. (2016). Infection risks associated with peripheral vascular catheters. Journal of Infection Prevention, 17(5), 207-213. 